\title{
Energized lung resections
}

\author{
Moishe Liberman, MD, PhD
}

\footnotetext{
From the Division of Thoracic Surgery, University of Montréal, Montréal, Québec, Canada; and CETOC CHUM Endoscopic Tracheobronchial and Oesophageal Center, Centre Hospitalier de l'Université de Montréal, Montreal, Quebec, Canada.

Disclosures: Dr Liberman receives research grant support from Ethicon Endosurgery.

Received for publication March 7, 2018; accepted for publication March 9, 2018; available ahead of print April 7, 2018.

Address for reprints: Moishe Liberman, MD, PhD, Division of Thoracic Surgery, Centre Hospitalier de l'Université de Montréal, Centre de Recherche du CHUM, Room: R04.402-1, 900 Rue Saint-Denis, Montreal, Quebec, Canada H2X 0A9 (E-mail: moishe.liberman@umontreal.ca).

J Thorac Cardiovasc Surg 2019;157:396

$0022-5223 / \$ 36.00$

Copyright (c) 2018 by The American Association for Thoracic Surgery

https://doi.org/10.1016/j.jtcvs.2018.03.036
}

In this edition of the Journal, Okada and colleagues ${ }^{1}$ report on a prospective feasibility study evaluating vascular energy sealing using the LigaSure Device (Medtronic, Louisville, Colo) in anatomic lung resection. The LigaSure Device is an advanced bipolar energy device. The study was designed to evaluate sealing in vessels up to and including $7 \mathrm{~mm}$ in diameter (both pulmonary arteries and veins) in 328 patients. This is the largest prospective trial to date evaluating the safety and feasibility of vascular energy sealing in anatomic lung resections. The single cohort trial was stopped and then changed after 128 patients were recruited because of a postoperative hemorrhage. The trial was reopened after the design was changed to a 2-cohort design. In the amended study, veins up to $7 \mathrm{~mm}$ in diameter and arteries up to $5 \mathrm{~mm}$ in diameter were sealed using the energy device. Data such as these are extremely important before widespread application of the device in clinical practice.

Energy application for pulmonary vessel control and ligation is extremely attractive because of the low profile of the device tip, the thin shaft of the instrument, and the ability of the energy device to be used for hilar dissection and lymph node dissection (Figure 1). Although multiple

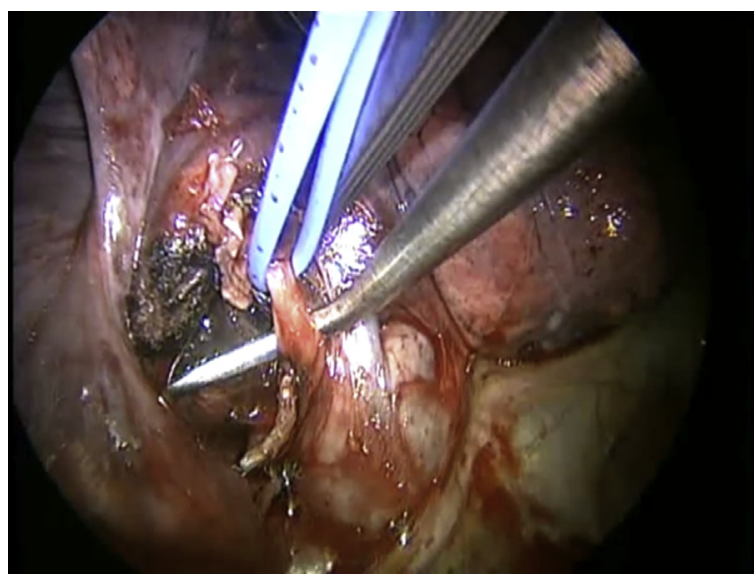

FIGURE 1. Pulmonary arterial branch ready for energy sealing in videoassisted thoracic surgery right middle lobectomy.

\section{References}

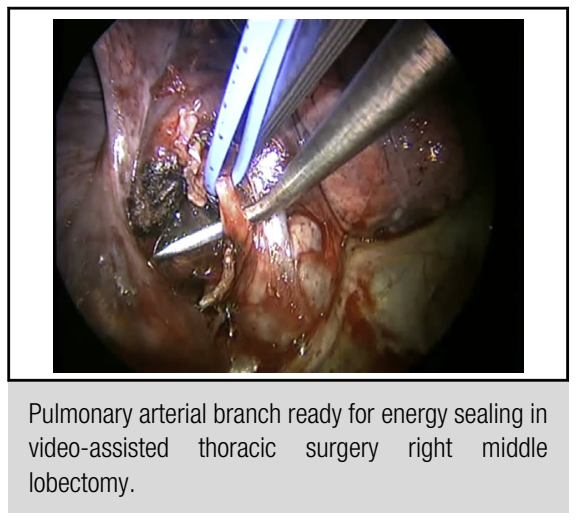

\section{Central Message}

Energy devices for pulmonary vessel ligation are extremely attractive because of their low profile, thin shaft, and the ability of the device to be used for hilar and lymph node dissection.

See Article page 388 .

studies have been published using pure ultrasonic energy for sealing pulmonary arteries, ${ }^{2-5}$ this is the first largescale study using an advanced bipolar device. It is interesting also because both veins and arteries were evaluated. It is hard to understand how there were so many pulmonary veins of 7 or less $\mathrm{mm}$ in diameter sealed in a study with such a high proportion of lobectomy $(73 \%)$ versus segmentectomy $(27 \%)$. In our experience, main lobar pulmonary veins are almost never less than $1 \mathrm{~cm}$ in diameter except for middle lobe veins. This may be related to patient characteristics in the specific study population.

I would strongly caution the reader in applying an advanced bipolar device for sealing pulmonary vessels in everyday practice during anatomic lung resection until further studies are done providing additional safety data.

1. Okada M, Miyata Y, Takamochi K, Tsutani Y, Oh S, Suzuki K. Prospective feasibility study of sealing pulmonary vessels with energy in lung surgery. J Thorac Cardiovasc Surg. 2019;157:388-95.

2. Liberman M, Khereba M, Goudie E, Kazakov J, Thiffault V, Lafontaine E, et al. Pilot study of pulmonary arterial branch sealing using energy devices in an exvivo model. J Thorac Cardiovasc Surg. 2014;148:3219-323.

3. Goudie E, Khereba M, Tahiri M, Hegde P, Thiffault V, Hadjeres R, et al. Pulmonary artery sealing with an ultrasonic energy device in VATS lobectomy. An animal survival study. Ann Thorac Surg. 2016;102:1088-94.

4. Goudie E, Thiffault V, Jouquan A, Lafontaine E, Ferraro P, Liberman M. Pulmonary artery sealing with ultrasonic energy in open lobectomy. A phase 1 clinical trial. J Thorac Cardiovasc Surg. 2017;153:1600-7.

5. Goudie E, Thiffault V, Jouquan A, Lafontaine E, Ferraro P, Liberman M. Phase 1 trial evaluating safety of pulmonary artery sealing with ultrasonic energy in VATS lobectomy. Ann Thorac Surg. 2018;105:214-20. 